\title{
An Examination of Students' Use of Technology for Non-Academic Purposes in the College Classroom
}

\begin{abstract}
Zachary G. C. Kornhauser ${ }^{1}$, Andrea L. Paul ${ }^{2}$, and Karen L. Siedlecki ${ }^{3}$
Abstract: Previous research has shown that students who use technology in the classroom for non-academic purposes suffer decrements to their academic performance. These findings are consistent with theories and research in cognitive science. However, no current study has examined the type of technology that students use in class, their reasons for using it, and whether they feel that it is acceptable to use it. The current study sought to quantitatively and qualitatively explore these questions across a sample ( $N=$ 105) of college students. Results reveal that the most common uses of technology in the classroom is text messaging and emailing, and that students regularly use technology for a variety of non-academic reasons. In addition, students commonly used technology in class because of boredom, and those students who used technology because of boredom scored lower than students who used technology in class for other reasons. Frequency of laptop and cell-phone use did not impact academic performance, however. Implications for this research are discussed.
\end{abstract}

Keywords: post-secondary education; media in education; pedagogical issues; teaching/learning strategies

Technology use and ownership have become ubiquitous amongst today's college students, many of whom are equipped with an array of mobile devices. For instance, estimates suggest that almost $90 \%$ of North American university students own laptop computers (Dahlstrom, Boor, Grunwald, \& Vockley, 2011). Other estimates suggest this figure is as high as 99\% (University of Virginia, 2009). The past decade has also witnessed the rapid introduction of an even more portable device- internet enabled smartphones, which are owned by $84 \%$ of college students today (Pearson Education, 2014).

Predictably, and perhaps inevitably, this increase in technology ownership across campuses corresponds with increases in the amount of software students use and the time they spend using it. Evidence suggests that, on average, students spend approximately 52 minutes per day using social networking sites, just over half an hour e-mailing, and nearly 45 minutes talking on a cell-phone or text messaging (Jacobsen \& Forste, 2011). Other research suggests that frequent email users ( $75 \%$ of students) send and receive an average of 25 emails a day, frequent text-messagers ( $74 \%$ of students) send an average of 84 text messages a day, and frequent Facebook users (58\% of students) check Facebook 13 times a day (Dahlstrom et al., 2011).

As technology ownership increases among college students in general, there has also been a documented rise of student technology use within the classroom. For instance, evidence suggests that $65 \%$ of students bring their laptops to class with them (Fried, 2008). Students

\footnotetext{
${ }^{1}$ Fordham University, Department of Psychology, 441 E. Fordham Road, Bronx, NY 10458, zkornhauser@fordham.edu

${ }^{2}$ Fordham University, andrealaurenpaul@gmail.com

${ }^{3}$ Fordham University, klsiedlecki@fordham.edu
} 
might use technology in class for a number of purposes, including gaming, social networking, and web browsing, none of which necessarily relate to the course material being presented (e.g., Hembrooke \& Gay, 2003; Witecki \& Nonnecke, 2015). Thus, students' access to technology in the classroom has the potential to distract them from course material.

Indeed, several studies show that when students have access to laptops in the classroom, they often engage in distractive multi-tasking behaviors (Fried, 2008; Hembrooke \& Gay, 2003; Kraushaar \& Novak, 2010). For instance, Kraushaar and Novak (2010) tracked student laptop use during class time through the installation of computer-monitoring software and found that while technology is often used in the classroom for course-related purposes, it also frequently used for 'distractive' purposes as well; the authors found that students opened an average of 40.7 non course-related web browser windows, which is twice as many windows that students opened for productive, or course-related purposes. Indeed, for every 100 productive windows students opened, they also opened 33 surfing and entertainment windows, 27 email windows, 43 instantmessaging windows, 87 PC operations windows, and 19 miscellaneous windows. Furthermore, $91 \%$ of students were observed using email during class, and $61 \%$ were observed using instant messaging programs.

Some colleges have started to implement strategies to combat this usage, including banning technology use during class, asking students who use laptops or other technology to sit in the front of the class for monitoring, or setting up systems which allow instructors to switch off the internet during class sessions (Young, 2006). These strategies have been implemented with the assumption that in-classroom technology use distracts from lecture and decreases academic performance, but is this really the case? In the following paragraphs, background theory on cognitive load and attention will be presented followed by an examination of the empirical literature on the relationship between in class technology use on academic performance.

Theories and research findings in cognitive science generally lead to the prediction that non-academic technology use in the classroom hinders learning and, consequently, academic performance. For example, early theories of attention have proposed it to be a bottleneck, in that we are presented with more information that we can process at any given time (Broadbent, 1958). Applied to the classroom setting, if use of academic technology is occupying the bottleneck then it can be assumed that less attention is being paid to course material.

A second, more recent approach to understanding the problems that non-academic technology use in the classroom might pose to learning is cognitive load theory (CLT). According to CLT, our cognitive architecture is designed to process information in certain manners (Sweller, 2012). From a CLT standpoint, certain knowledge and skills, such as recognizing faces and learning how to speak, are biologically ingrained and occur outside of our conscious awareness. These skills are referred to as biologically primary knowledge. On the other hand, biologically secondary knowledge is knowledge that we are not adapted to acquire, and thus must do so consciously and effortfully. An example of this type of knowledge would be educational information taught in college (Sweller, 2012). In order to acquire biologically secondary knowledge we utilize cognitive processes such as working memory, which is an information processing and storage unit that is limited both in capacity and in duration (Leahy \& Sweller, 2011). Due to the limitations inherent to our working memory systems, we can only process a limited number of items at any given time. Every task we complete competes for our attention, and those that we attend to have a cognitive cost on our working memory (Sweller, 1988). 
The notion of how much cognitive load we can manage at one time also depends on the information itself and the way that it is presented. Intrinsic cognitive load refers to the complexity of the material being taught, and cannot be modified. Extraneous cognitive load, on the other hand, depends on the way that material is imparted, and is very much within the control of the instructor (Wong, Leahy, Marcus, \& Sweller, 2012).

According Sweller (2011), we are most successful in learning information when that information does not exceed our working memory capacity, and the extraneous cognitive load is low. Thus, instructors who are able to present material within the limits of students' processing capacity are most likely to facilitate effective learning environments for their students (Sweller, 2012). However, this model would predict that student learning would decrease in instances where students are straining their working memory by using technology for non-academic purposes while also attempting to pay attention to course material. Furthermore, this model also posits that the use of technology can present extraneous cognitive load on students, even if this technology is being used for educative purposes (Sweller, 2012).

A further cognitive perspective through which non-academic technology use in the classroom can be understood is divided attention, or our ability to focus on two tasks being performed at the same time. Research on divided attention has generally demonstrated that attending to two tasks simultaneously, such as listening to a lecture while also using a computer for non-academic purposes, decreases our ability to perform either task effectively. Some of the research on the topic has found that performing a concurrent activity while also attempting to encode a memory leads to decrements in recalling that memory (Baddeley, Lewis, Eldridge \& Thomson, 1984). In these instances, it appears that retrieving information becomes difficult if that information was not encoded well in the first place.

The above theoretical perspectives suggest that technology use in the classroom leads to decrements in academic performance, and research on the topic has generally revealed this to be the case. Multiple researchers have found a negative relationship between non-academic technology usage and academic performance (Fried, 2008; Junco \& Cotten, 2012; Kraushaar \& Novak, 2010; Wood, et al., 2012). For instance, Fried (2008) demonstrated that laptop usage was significantly and negatively related to class performance (out of a score of 100) even when other factors have been controlled for. Further, Kraushaar and Novak (2010) demonstrated that use of distractive technologies during class was inversely related to multiple measures (e.g., quiz score, final exam score) of academic performance. Wood et al. (2012) found that students who do not use technology in class outscored students who did use technology on a multiple-choice quiz. Finally, Junco and Cotton (2012) showed that the detrimental impact of technology extends beyond the classroom, as using Facebook while completing schoolwork outside of class was negatively associated with academic performance.

In addition, research has shed light on the specific technologies that lead to the aforementioned decrements in academic performance, including laptops (Fried, 2008; Hembrooke \& Gay, 2003), text-messaging, (Rosen, Lim, Carrier, \& Cheever, 2011), and Facebook use (Wood et al., 2012; Junco \& Cotten, 2012). These findings are consistent with those from cognitive science that predicts that attempting to pay attention to more than one stimulus will affect students' ability to accurately pay attention to either stimulus.

Previous research has demonstrated that there is a negative relationship between nonacademic technology use and academic performance (Fried, 2008; Kraushaar \& Novak, 2010; Junco \& Cotten, 2012; Wood, et al., 2012). However, many questions surrounding students' use of technology in the classroom remain unanswered. Specifically, no studies to date have 
adequately examined what sorts of non-academic technology are being used during class, why students are using it, and their thoughts regarding the acceptability of using it. Are students using some forms of technology more than others? Also, what factors underlie their reasons for using it? Might students be having difficulty concentrating on the course material for long stretches of time, or are their instructors not adequately engaging them? Finally, do students feel it is acceptable to use technology for non-academic purposes during class? The purpose of the current study is to quantitatively and qualitatively examine these questions, while also examining the relationship between in-class technology use for non-academic purposes and academic performance as measured by course grade. The results may have important implications for the way that college classes are taught, and the way that students' use of technology is approached by instructors and college administrators alike.

\section{Method}

\section{Participants and procedure}

Participants were recruited for this study through an "event” created on Facebook. Undergraduate students from across the United States were invited to the event. If they chose to "attend" the event, the event page held a short explanation with a link to an online survey. Links to the online survey were also posted on related websites and were e-mailed to selected undergraduate classes at Fordham University, a private college in New York City. Inclusion criteria included being an undergraduate college student, and having completed four courses within a year of completing the survey. One hundred and five participants, comprising 53 females (50.5\%) and 21 males (20.0\%) (31 participants declined to state gender), completed the survey.

\section{Materials}

Participants completed a survey designed to assess frequency and types of technology use and the relationship between these variables and academic achievement (see the Appendix). Participants were instructed to reflect on an undergraduate course they had taken in the past year. For this class they reported the name of the course, the frequency (always, often, sometimes, rarely, or never) of using a laptop and cell phone for non-academic purposes, how many minutes they spent using technology per class meeting, and the grade they received in the course, on a scale from A to F. They were also asked why they used technology in class, and the respondents were asked to check all the answers that applied among the following options: boredom, long class, needed to talk to someone, needed information for class, felt the need to stay connected to the outside world, or other (in which the respondents were given room to elaborate).

In addition, participants answered questions regarding gender, college year, their overall GPA, and their major GPA. Finally, participants also answered the following qualitative questions:

1. Acceptability: Do you think it is acceptable to use technology in the classroom? (First, they selected "Yes", "No", or "Sometimes" and then filled-in an open-ended response box labeled "Explain”). 
2. Type of use: If you use a cell phone or computer for non-academic purposes in the classroom, how would you describe your use? (e.g., long chunks of time browsing the internet, shooting a quick text message, etc.)

3. Variation: Do you use technology for non-academic purposes more frequently in certain classes? Why? (e.g., a particular subject, a particular professor, a longer class, etc.)

\section{Results}

\section{Quantitative analyses}

Descriptive statistics were conducted to determine which technologies students used during class, how often students used them, and their reasons for using them. In regards to technology use, results revealed that 45 participants (43.3\%) reported using laptops in class and 83 (79.8\%) reported using cell-phones in class. One response was missing from both calculations. Laptop use was positively correlated with cellphone use $(r=.41, p<.01)$ and with average number of minutes of using technology during class $(r=.57, p<.01)$. Cellphone use was also positively correlated with average number of minutes of using technology during class $(r=.40, p<.01)$.

Of those participants who reported using laptops in class, participants most commonly reported using them in every class $(n=16$; 35.6\%) followed by rarely using them $(n=12$; 26.7\%). Of those participants who reported using cell-phones in class, participants most commonly reported using them rarely ( $n=28$; 33.7\%) followed by using them every class ( $n=$ 20; 24.1\%). A complete list of participants' reported frequency of laptop and cell-phone use can be found in Table 1. Results of a chi-square analysis indicated that students who reported using laptops frequently in class also tended to use cell-phones frequently in class, while students who rarely or never used laptops in class also tended to rarely or never use cell-phones in class $\left(\chi^{2}=\right.$ 33.46, $p<.05)$.

Table 1. Participants' frequency of laptop and cell-phone use in class

\begin{tabular}{lcccc}
\hline & $\begin{array}{c}\text { Laptop use } \\
(N=45)\end{array}$ & $\%$ & $\begin{array}{c}\text { Cell-phone use } \\
(N=83)\end{array}$ & $\%$ \\
\hline & 16 & 35.6 & 20 & 24.1 \\
Every class & 11 & 24.4 & 19 & 22.9 \\
Most classes & 6 & 13.3 & 16 & 19.3 \\
Some classes & 12 & 26.7 & 28 & 33.7 \\
Rarely & & & & \\
\hline
\end{tabular}

Reasons for use. Regarding reasons for using technology in class, 55 (52.9\%) reported that they did so out of boredom, 33 (31.7\%) reported that they did so due to the length of the class, 27 (26\%) reported that they did so because they needed someone to talk to, $22(21.2 \%)$ reported they did so to look up information for class, 19 (18.3\%) reported they did so because they felt they needed to be connected to the outside world, and 18 (17.3\%) responded with 'other.' More information on the reasons for use can be found in the qualitative analysis section. Chi-square analyses were conducted to determine if duration of laptop and cell-phone use (e.g., 
always, sometimes, rarely, and never) were correlated with particular reasons for use (e.g., boredom, length of class, needed to talk to someone). Results revealed that students who always used laptops tended to do when they felt their classes were too long $\left(\chi^{2}=19.27, p<.01\right)$, and used cell-phones when they felt their classes were too long $\left(\chi^{2}=15.88, p<.01\right)$ or when they were bored $\left(\chi^{2}=33.04, p<.01\right)$.

Technology use and academic performance. Chi-square analyses were conducted to examine the relationship between in-class technology use and course grade. For course grade, due to the large portion of students who received course grades of 'A,' data was coded in such a way that grades were coded as 'A' $(n=59,56.2 \%)$ or less than 'A' $(n=44,41.9 \%)$. One response was missing from the calculation. Analyses revealed that duration of laptop and cellphone use in class did not significantly impact course grade $\left(\chi^{2}=6.44, p=.96 ; \chi^{2}=7.05, p=\right.$ .13). Further analyses were conducted to determine if particular reasons for using laptops and cell-phones related to course grade. Results indicated that students who used technology out of boredom $\left(\chi^{2}=4.83, p<.05\right)$ tended to score lower than students who used technology in class for other reasons.

Acceptability of technology use. Additional analyses were conducted to examine whether individuals who answered "yes" to the question of $(n=37.1 \%)$ "Do you think it is acceptable to use technology in the classroom?" differed in use of in-class technology compared to individuals who answered that it is "sometimes" acceptable $(n=44 ; 62.9 \%)$. Only four participants answered "no" to the above question and were therefore excluded from the analyses. Independent sample $t$-tests indicated that those individuals who thought that technology use is always acceptable reported using laptops and cell-phones more often, $t(68)=-3.32, p=.001$ and $t(68)=-2.62, p=.011$.

\section{Qualitative analyses}

Categories were created to describe participant responses for each open-ended question (type of use, acceptability, and variation) and two independent raters classified each participant response into as many categories as were appropriate. Because one response could be classified into more than one category, the percentages in the tables below exceed $100 \%$. The mean correlation between the two independent raters across all the categories was .88 for type of use, .77 for acceptability, and .86 for variation. Responses that were categorized differently by the raters were resolved in a meeting between the two raters.

Type of use. Frequencies of the responses for the type of use question (If you use a cell phone or computer for non-academic purposes in the classroom, how would you describe your use?) are presented in Table 2. Seventy individuals answered the question, and the most frequent response ( $n=50,71.4 \%$ ) to the question was that they texted in class. The next most frequent response was that they used their computer for non-academic purposes for browsing or surfing the internet $(n=10,14.3 \%)$, and checking email $(n=9,12.9 \%)$. In addition, 43 students $(61.4 \%)$ used a term (quick, brief) in their descriptions to signify that their use was done quickly.

\section{Table 2. Themes identified in the open-ended responses to the "Type of Use" question}

\begin{tabular}{lll}
\hline TYPE OF USE $(N=70)$ & Total & $\%$ \\
\hline
\end{tabular}

\section{Texting}

$50 \quad 71.4$

Journal of Teaching and Learning with Technology, Vol. 5, No. 1, July 2016 jotlt.indiana.edu 


\begin{tabular}{lcc} 
Browsing/surfing & 10 & 14.3 \\
Checking email & 9 & 12.9 \\
Chatting with friends & 6 & 8.6 \\
Playing games & 4 & 5.7 \\
Facebook & 4 & 5.7 \\
Checking the time & 2 & 2.9 \\
Look something up & 1 & 1.4 \\
Working on work from other classes & 1 & 1.4 \\
Multitasking & 1 & 1.4 \\
Check messages, but not replying & 1 & 1.4 \\
\hline
\end{tabular}

Acceptability of use. Sixty-three individuals provided an answer to the acceptability question (Do you think it is acceptable to use technology in the classroom? Explain). The most frequent response concerning using technology for academic purposes, included taking notes ( $n$ $=25,39.7 \%)$. Other common responses included using technology in times of emergency or when needing to communicate with someone else $(n=13,20.6 \%)$, and when used as a resource to look something up ( $n=12,19 \%)$. A complete list of identified themes is presented in Table 3 . An example of a response that was categorized under Academic purposes is "Only when it is called for, or for note-taking. I think it is extremely rude to use technology to communicate or play games during class." An example of a response categorized under Boredom is "Sometimes a class is too long or just too boring. Without the use of technology, I wouldn't make it through the class without falling asleep.” The following response was categorized under several categories (Academic purposes, Beneficial learning tool, Resource for looking things up, and Multitasking): "If one feels confident multitasking then they should be able to use technology. It can also be a helpful tool to find out information about the subject and/or take notes more quickly/efficiently.”

Table 3. Themes identified in the open-ended responses to the “Acceptability” question

\begin{tabular}{lcc}
\hline ACCEPTIBILITY $(N=63)$ & Total & $\%$ \\
\hline & & \\
Academic purposes (taking notes, if computers are & 25 & 39.7 \\
necessary for class) & 13 & 20.6 \\
When necessary to communicate/ Emergency & 12 & 19 \\
When used as a resource to look things up & & \\
Comfort with multi-tasking/ doesn't hinder the learning & 6 & 9.5 \\
process & 5 & 7.9 \\
Depends on class size/structure & 4 & 6.3 \\
Beneficial learning tool & 4 & 6.3 \\
Unless disturbing others & 4 & 6.3 \\
Boredom & 2 & 3.2 \\
Used in the "real world" & 1 & 1.6
\end{tabular}


Variation of use. As shown in Table 4, 68 participants responded to the variation question (Do you use technology for non-academic purposes more frequently in certain classes? Why?). The most common response was that non-academic technology use was used in classes that were considered long ( $n=21,30.9 \%)$. For instance, one response categorized under Long class and Class size is "I use technology for non-academic purposes more frequently in larger classrooms with longer class periods.” Boredom ( $n=16,23.5 \%)$ and having a boring, unengaging, or dull professor ( $n=14,20.6 \%$ ) were also commonly cited as reasons for using technology in class. An example of a response that was categorized in both of the aforementioned categories is, "I do when professors are extremely dull or if I am not interested in the subject material at all.” Eleven participants (16.2\%) answered that the type of class did not influence their use of technology for non-academic purposes.

Table 4. Themes identified in the open-ended responses to the "Variation" question

\begin{tabular}{lcc}
\hline VARIATION $(N=68)$ & Total & $\%$ \\
\hline & & \\
Long class & 21 & 30.9 \\
Boredom & 16 & 23.5 \\
Boring/ unengaging/ dull professor & 14 & 20.6 \\
No difference & 11 & 16.2 \\
Non-interactive classes , lectures & 6 & 8.8 \\
Classes that require technology/ when a computer is & & \\
provided & 5 & 7.4 \\
Depending on interest in subject matter & 5 & 7.4 \\
Size of class & 4 & 5.9 \\
Significant down time, a break during class & 3 & 4.4 \\
Depending on how much prof noticed or cared & 3 & 4.4 \\
Class is easy & 2 & 2.9 \\
During a group activity & 1 & 1.5 \\
Seminar oriented classes & 1 & 1.5 \\
Professor teaches from textbook & 1 & 1.5 \\
\hline
\end{tabular}

\section{Discussion}

The current study aimed to examine what type of technology students used during class, how often they used it, their reasons for using it, and their thoughts about the acceptability of its use, while also examining whether in-class use of technology led to decrements in academic performance. Results indicate that many more students use cell-phones in class than laptops, and that students most commonly use academic technology when they are in a long class or when they are bored. Also, most students believe it is not acceptable or is only sometimes acceptable to use technology in class for non-academic purposes.

One main objective of the study was to examine whether using technology for nonacademic purposes in class led to decrements in academic performance. In contrast with previous Journal of Teaching and Learning with Technology, Vol. 5, No. 1, July 2016 jotlt.indiana.edu 
research that found that using such technology use lead to decrements in academic performance (e.g. Fried, 2008; Junco \& Cotten, 2012; Kraushaar \& Novak, 2010), the current study did not find this to be the case.

One possible explanation for why the current study yielded discrepant findings from previous studies may be attributed to the nature of our sample. Of the 103 participants who provided their course grade, 59 reported receiving 'A's,' 36 reported receiving 'B's,' and only 8 reported receiving a course grade lower than a 'B.' This relative homogeneity in reported grades may be a function of the sample of participants, or it could be due to the influence that social desirability may have on participants' responses. A second explanation for our findings is that when asked to describe the type of technology use that they engaged in during class, a large portion of the participants (61.4\%) reported that they did so either briefly or quickly. Examples of responses to the question of "If you use a cell phone or computer for non-academic purposes in the classroom, how would you describe your use?” include: “quick text messages, brief Facebook checks”; “Quick texts or looking something up really quickly”; “checking messages quickly, or writing a quick text/email.” A total of 34 participants (49\%) specifically mentioned that they texted during class and that they did so quickly (i.e., "shooting a quick text message") in their response to the type of usage question. If students are not using technology consistently throughout the duration of a class for non-academic purposes, then technology use may not be any more detrimental than usual in-class distractions (e.g., daydreaming, doodling). However, it worth noting that in-class technology use for non-academic purposes may adversely influence students sitting near the student using the technology for non-academic purposes. Thus, technology use differs from usual in-class distractions because those distractions are unlikely to affect others, whereas technology use has a high potential of distracting others. Future research could focus on the difference between brief and prolonged in-class technology use for nonacademic purposes and how it affects academic achievement as measured by course grade, and also how it affects students who are seated near individuals who use technology for nonacademic purposes.

The other major aim of the study was to determine what type of technology participants were using in the classroom, their reasons for using it, and their thoughts on the acceptability of using it. The vast majority (80\%) of participants reported using cell-phones in class, while comparatively fewer reported using laptops (43\%) in class. This finding is interesting because it might be assumed that computers would be used more commonly for non-academic purposes than cell-phones, since presumably using computers would be more discreet as they also can be used for academic purposes in the class. On the other hand, cell-phones are more portable than computers, so perhaps more students bring them to class than they do computers.

In terms of reasons for using technology, according to the qualitative analyses the most common responses provided by participants was that they did so because they felt the class was long, they were bored, or they felt that their instructor was boring or unengaging. In regards to the length of class as a reason for using technology, a question that should be considered is how class time relates to students' attention span. In comparison to high school classes which are typically less than 50 minutes, college classes are commonly 75 minutes or longer (Reardon, Payan, Miller, \& Alexander, 2008).

Boredom in academic settings is composed of lack of psychological arousal or cognitive stimulation, and desires to escape the feelings through disengagement (Pekrun, Goetz, Daniels, Stupinsky, \& Perry, 2010). According to this definition, students who are bored in class may very well disengage with the material and use technology for non-academic purposes, so it is not 
surprising that boredom was a recurring theme mentioned by students for using technology in class. It is not known, however, what specifically led to students becoming bored or disengaged. The question should be explored as to whether it is the material that students are bored with, the instructor, the instructor's teaching style, or some combination of these factors. Also, worth noting is that according to previous research, boredom correlates negatively with academic achievement. In line with this previous research, we found that students who used technology because of boredom tended to score lower than students who used technology in class for other reasons.

Regarding participants' thoughts on the acceptability of using technology in class, many participants (40\%) reported that it was acceptable if such usage had an academic purpose, while fewer participants reported feeling it was acceptable to use technology for non-academic purposes. When asked to explain their position, most individuals indicated that using computers to take notes and get information for class were the most acceptable uses of technology. One respondent expressed that it is unreasonable for instructors to forbid computer use, as fast lecture pace demands quick note taking. Other students felt that looking up information pertaining to class material aids in class discussions, and the Google search engine can be used as a learning tool to clarify unclear points in lecture. Participants who felt that technology was only acceptable in certain circumstances expressed the view that technology use can be distracting to other students and disrespectful to instructors. One individual felt that technology use for nonacademic purposes only occurs with students who do not care about their education, while another felt that the experience of learning is diminished with the use of technology. For those participants who did report it was acceptable to use technology for non-academic purposes, common reasons mentioned were that they felt the class was easy or as long as they were not disturbing others it was acceptable. A few respondents mentioned technology use as a way of keeping awake in class and expressed that being distracted was more beneficial than being asleep.

It is interesting to note the discrepancy of the large amount of participants who reported using technology for non-academic purposes in class, compared to the smaller number of participants who felt it was acceptable to use technology for non-academic purposes. According to classical cognitive dissonance theory (Festinger, 1957), people experience tension when they engage in an activity that is inconsistent with their beliefs or attitudes. People then become motivated to resolve this tension by changing their existing beliefs or by developing new ones that are compatible with their behaviors. Applied to the current study, it might be assumed that participants who frequently used technology for non-academic purposes would develop a rationale for why their use was acceptable rather than using it but believing it was not acceptable to use in the classroom. Not surprisingly, individuals who felt technology use was always acceptable also tended to use laptops and cell phones more often.

While the current study yields interesting findings regarding students' use of technology during class, it is not without limitations. Chief among these limitations is the sample of participants used for the study. As mentioned earlier, the participants in this study achieved relatively homogenous grades, as the vast majority of participants in this study achieved grades of a ' $\mathrm{B}$ ' or higher.

Future research should seek to build on the current findings by examining some areas of inquiry that the current study was not able to address. For instance, future research should seek to determine whether technology use is prevalent in classes that are shorter in duration, and whether in-class technology use could possibly be decreased by diminishing the length of class or by the 
instructor offering breaks during the course of class. In addition, future research should seek to identify effective strategies for preventing or managing students' use of technology for nonacademic purposes. As part of the current study, the authors contacted university professors regarding what methods they employed to curb or prevent such usage of technology. A number of responses were received in regards to this inquiry, and strategies that were identified as being successful included having Teaching Assistants monitor technology use, adding disclaimers discouraging such usage in the syllabus, enacting institution-wide policies with standard penalties for using technology, asking students to vote on an acceptable policy at the start of each semester, integrating different forms of technology into the class, and designating particular times in the class during which technology can be used. Since these methods have only anecdotally been identified as being effective, future research should seek to empirically examine the effectiveness of these methods. The benefits of identifying effective methods of managing students' usage of technology are more than academic; if such teaching methods can be employed on a large scale, then our educational system can better prepare a more educated populace.

\section{Appendix 1: Technology Use Questionnaire}

For "Section I", please reflect on an undergraduate class you have completed in the past year.

\section{SECTION I: CLASSROOM ACTIVITY}

CLASS 1: Name of class

1. How often did you use your laptop in class other than to take notes? (ex. Internet or Games)

Always (Every Class)

Often (Most Classes)

Sometimes (Some Classes)

Rarely (Very Few Classes)

Never

2. How often did you use your cell phone in class? (ex. Texting, Internet, or Games)

Always (Every Class)

Often (Most Classes)

Sometimes (Some Classes)

Rarely (Very Few Classes) 
Kornhauser, Paul, and Siedlecki

Never

3. Why did you use technology during class? (Select all that apply)

Boredom

Long Class

Needed to talk to someone

Needed information for class

Felt the need to stay connected to the world outside the classroom

Other (explain)

4. What grade did you receive in this class?

$\mathrm{A} \_$B__ C

5. Average number of minutes you used technology per class meeting

\section{SECTION 2:}

Are you:

Male__ Female

What year are you in school?

Freshman Sophomore Junior Senior

What is your:

Overall GPA___ Major GPA

Rank the level of difficulty of your university

Extremely Challenging

Challenging

Average

Easy

Journal of Teaching and Learning with Technology, Vol. 5, No. 1, July 2016 jotlt.indiana.edu 
Kornhauser, Paul, and Siedlecki

Extremely Easy

Do you think it is acceptable to use technology in the classroom?

Yes___No___ Sometimes

Explain:

If you use a cell phone or computer for non-academic purposes in the classroom, how would you describe your use? (ex. Long chunks of time browsing the internet, shooting a quick text message, etc.)

Do you use technology for non-academic purposes more frequently in certain classes? Why? (ex. a particular subject, a particular professor, a longer class, etc.)

\section{References}

Baddeley, A., Lewis, V. V., Eldridge, M. M., \& Thomson, N. N. (1984). Attention and retrieval from long-term memory. Journal of Experimental Psychology: General, 113(4), 518-540.

Broadbent, D. (1958). Perception and Communication. London: Pergamon Press.

Dahlstrom, E., De Boor, T., Grunwald, P., \& Vockley, M. (2011). The ECAR national study of undergraduate students and information technology, 2011. Boulder, CO: EDUCAUSE Center for Applied Research.

Fried, C. B. (2008). In-class laptop use and its effects on student learning. Computers \& Education, 50(3), 906-914.

Festinger, L. (1957). A Theory of Cognitive Dissonance. Stanford, CA: Stanford University Press.

Hembrooke, H., \& Gay, G. (2003). The laptop and the lecture: The effects of multitasking in learning environments. Journal of Computing in Higher Education, 15(1), 46-64.

Jacobsen, W. C., \& Forste, R. (2011). The wired generation: Academic and social outcomes of electronic media use among university students. Cyberpsychology, Behavior 
Kornhauser, Paul, and Siedlecki

\& Social Networking, 14(5), 275-280.

Junco, R., \& Cotten, S. R. (2012). No A 4 U: The relationship between multitasking and academic performance. Computers \& Education, 59(2), 505-514.

Kraushaar, J. M., \& Novak, D. C. (2010). Examining the affects of student multitasking with laptops during the lecture. Journal of Information Systems Education, 21(2), 241251.

Leahy, W., \& Sweller, J. (2011). Cognitive load theory, modality of presentation and the transient information effect. Applied Cognitive Psychology, 25(6), 943-951.

doi:10.1002/acp.1787

Pearson Education (2014). Pearson student mobile device survey: College students. New York, NY: Pearson Education.

Pekrun, R., Goetz, T., Daniels, L. M. Stupinsky, R. H., \& Perry, R. P. (2010). Boredom in achievement settings: Exploring control-value antecedents and performance outcomes of a neglected emotion. Journal of Educational Psychology, 102(3) 531-549.

Reardon, J., Payan, J., Miller, C., \& Alexander, J. (2008). Optimal class length in marketing undergraduate classes: An examination of preference, instructor evaluations, and student performance. Journal of Marketing Education, 30(1), 12-20.

Rosen, L.D., Lim, A. F., Carrier, L. M., \& Cheever, N. A. (2011) An empirical examination of the educational impact of text message-induced task switching in the classroom: Educational implications and strategies to enhance learning. Psicologia Educativa, 17, 163-177.

Sweller, J. (1988) Cognitive load during problem solving: Effects on learning. Cognitive Science, 12, 257-285.

Sweller, J. (2011). Cognitive Load Theory. Psychology of Learning And Motivation, 55, 37-76.

Sweller, J. (2012). Human cognitive architecture: Why some instructional procedures work and others do not. In K. R. Harris, S. Graham, T. Urdan, C. B. McCormick, G. M. Sinatra, J. Sweller (Eds.) , APA educational psychology handbook, Vol 1: Theories, constructs, and critical issues (pp. 295-325). Washington, DC: American Psychological Association. doi:10.1037/13273-011

University of Virginia, (2009). UVA first year student computer inventory. Retrieved from http://its.virginia.edu/students/inventory/2009/.

Witecki, G., \& Nonnecke, B. (2015). Engagement in digital lecture halls: A study of student course engagement and mobile device use during lecture. Journal of Information 
Kornhauser, Paul, and Siedlecki

Technology Education: Research, 14, 73-90.

Wood, E., Zivcakova, L., Gentile, P., Archer, K., De Pasquale, D., \& Nosko, A. (2012). Examining the impact of off-task multi-tasking with technology on real-time classroom learning. Computers \& Education, 58(1), 365-374.

Wong, A., Leahy, W., Marcus, N., \& Sweller, J. (2012). Cognitive load theory, the transient information effect and e-learning. Learning and Instruction, 22, 449-457. doi: 10.1016/j.learninstruc.2012.05.004

Young, J. R. (2006). The fight for classroom attention: Professor vs. laptop. Chronicle of Higher Education, 52(39), A27-A29. 